\title{
Poesía en la escuela: los maestros, sus lecturas y sus creencias
}

\author{
Florencia Lamas \\ Escuela Normal Superior $N^{\circ}$ 4, Buenos Aires
}

(Texto recibido 29 de diciembre de 2016; aceptado 30 de mayo de 2017; versión final 05 de enero de 2018)

DOI: https://doi.org/10.5565/rev/jt13.699

Resumen: El artículo presenta los resultados de un estudio de caso en el que se exploraron las creencias de dos docentes en torno a la poesía y su didáctica en el segundo ciclo de la educación primaria. A partir de datos recogidos a través de relatos de vida y entrevistas, se analizó el perfil lector, el contenido de las creencias y los factores que inciden en su conformación. Los resultados evidencian que el impacto de las trayectorias de formación en los diferentes niveles es mayor que el del perfil lector del género.

Palabras clave: pensamiento del profesor, perfil lector, didáctica de la poesía en la educación primaria, formación docente inicial

\begin{abstract}
This article presents the results of a case study on the beliefs of two teachers about poetry and its didactics in the second cycle of primary education. The reader profile, the content of the beliefs and the factors that influence their development were analyzed from data collected through life stories and interviews. The results show that the impact of career paths at the different levels is higher than that of the genre reading profile.
\end{abstract}

Key words: teachers' beliefs, reader profile, poetry didactics in primary education, initial teacher training

Resum: L'article presenta els resultats d'un estudi de cas en el qual es van explorar les creences de dos docents al voltant de la poesia i la seva didàctica en el segon cicle de l'educació primària. A partir de dades recollides a través de relats de vida i entrevistes, es va analitzar el perfil lector, el contingut de les creences i els factors que incideixen en la seva conformació. Els resultats evidencien que l'impacte de les trajectòries de formació en els diferents nivells és més gran que el del perfil lector del gènere.

Paraules clau: pensament del professor, perfil lector, didàctica de la poesia en l'educació primària, formació docent inicial 


\section{"Una historia particular de amor y desamor"}

El título de este apartado remite a una reflexión que Teresa Colomer (2005) propone acerca de la relación entre la escuela y la lectura poética, al tiempo que afirma: "Muy pocos libros leídos en la escuela son de poesía" (p. 235). Las referencias a la posición marginal del texto poético en las aulas hispanoamericanas de los diferentes niveles de enseñanza se reiteran tanto en la bibliografía especializada como en jornadas, congresos ${ }^{1} \mathrm{y}$ conversaciones informales con docentes.

A esto se suma el cuestionamiento al tipo de prácticas que se realizan en torno a la poesía cuando esta se hace presente. En este sentido, se habla, por ejemplo, de "abordajes didácticos empobrecidos" (Mathieu, 2012, p. 184), se señala que se "tiende a 'usar' la poesía con segundos propósitos, dejando de lado el aspecto estético" (Boland, 2011, p. 43), o se afirma que "la escuela ha construido una visión sesgada de la poesía" (Bombini y Lomas, 2016, p. 6) ${ }^{2}$. Aunque sabemos de muchas experiencias interesantes y potentes que se concretan en las aulas (Ramos, 2010; Negri y Correa, 2014; Bajour, 2016), su número sigue siendo escaso.

¿Qué factores inciden para que la poesía ocupe este lugar secundario en la escuela? Creemos que la respuesta a este interrogante exigiría examinar en profundidad múltiples variables que se traman y operan de diferente manera en los distintos contextos. Numerosas investigaciones educativas de las últimas décadas han centrado su mirada en las actuaciones de los profesores y en la diversidad de factores que inciden en ellas. En relación con la educación literaria, entre estos factores se cuentan el perfil lector del docente y sus creencias sobre la didáctica de la literatura, sobre los que hemos elegido centrarnos en este trabajo.

¿Cuáles son los contenidos de las creencias de los docentes acerca de la didáctica de la poesía y qué relación se establece entre ellas, su perfil lector y su trayectoria de formación? A esta pregunta buscamos aportar alguna línea de reflexión a través de un estudio de caso. Nos interesa explorar en aquellas creencias para que nos ayuden a construir líneas explicativas acerca de las dificultades de la presencia de la poesía en las aulas. Confiamos en que este conocimiento nos ofrezca herramientas para fortalecer la formación docente inicial.

\section{Las creencias de los docentes y el perfil lector}

Las investigaciones sobre el pensamiento del profesor utilizan diversidad de conceptos para categorizar y describir su objeto de estudio (Cambra, 2000; Borg, 2003). En este trabajo 
adoptamos la denominación de creencias y el modelo explicativo propuesto por Cambra (2000), quien destaca que están conformadas por conjuntos de elementos articulados que forman sistemas constituidos por creencias (dimensión personal), representaciones (dimensión social) y saberes (convencionalmente aceptados). Los constituyentes de estos sistemas de creencias se orientan a diversas dimensiones: los contenidos y materias que se enseñan, las posibilidades de aprendizaje y desempeño de los estudiantes, el propio rol como enseñante, entre otros.

El carácter complejo, ecléctico, heterogéneo y dinámico de estas creencias constituye un punto de acuerdo en las investigaciones y su conformación responde a la incidencia de múltiples factores. Entre ellos, Munita (2014) releva: las experiencias de escolarización previa de los maestros, la formación docente (inicial y continua), la propia práctica profesional, las prescripciones curriculares y los factores contextuales (imaginarios vehiculados por la sociedad, por el sistema educativo y/o por la/s institución/es). Por su parte, Borg (2003) enfatiza el impacto de las experiencias que los profesores han tenido en sus trayectorias escolares, y señala que las creencias establecidas tempranamente son muy resistentes al cambio y siguen constituyendo un modelo fuerte no obstante la formación de grado.

El impacto de la formación docente en la modificación de las creencias es objeto de debate en la investigación. Mientras algunos concluyen que su incidencia es escasa, otros ponen en entredicho esas conclusiones, como apunta Munita (2014) quien -luego de ofrecer un recorrido por trabajos en torno a la educación literaria- destaca el impacto que ha tenido la incorporación de nuevos dispositivos didácticos a la formación docente en educación literaria (entre ellos, los escritos de respuesta lectora, la discusión literaria o los clubes de lectura). En esta línea, Dueñas, Tabernero, Calvo y Consejo (2014) destacan la fuerte incidencia de las trayectorias lectoras escolares en relación con el perfil lector de los futuros docentes, pero confían en el poder transformador que en ese perfil pueden tener las experiencias de lectura gratificantes durante su formación inicial.

El conjunto de factores mencionados incidiría en cómo los profesores perciben su tarea y en las decisiones que toman en sus clases (Cambra, 2000). No obstante, es preciso evitar los reduccionismos y tener presente que así como las creencias inciden en las prácticas, estas últimas y otros factores contextuales pueden modificar las primeras (Munita, 2014; Borg en Birello, 2012). 
En cuanto al impacto del perfil lector del docente en sus actuaciones, en un artículo de 1990, Dubois alerta sobre el "factor olvidado" en la formación de maestros de ese entonces: la preocupación centrada en lo que el docente debía saber y lo que debía hacer omitía reflexionar sobre "la cualidad de lector y escritor que debe poseer el maestro" (p. 32). Ese planteo fue retomado en investigaciones posteriores, como las de Applegate y Applegate (2004), que se preguntan si los docentes que no sienten amor por la lectura pueden generar motivación en los niños y afirman que los que son lectores entusiastas son más proclives a utilizar estrategias de enseñanza que promueven el compromiso lector. Por su parte, Granado y Puig (2014) dan cuenta de estudios que llegan a conclusiones similares sobre la relación entre el perfil lector de un docente y las prácticas de educación lectora que ofrece, tanto en lo que se refiere a fomentar el entusiasmo por los libros como al traslado del tipo de prácticas que él mismo realiza.

\section{Metodología}

Como señalamos, el propósito de este trabajo fue explorar en las creencias de docentes de educación primaria en torno a la poesía y su didáctica, y en la relación que se establece entre los contenidos de esas creencias y dos factores: el perfil lector de los sujetos y su trayectoria de formación.

En función de estos objetivos, realizamos una investigación cualitativa centrada en el estudio de caso y en el enfoque biográfico-narrativo, que permite conocer el perfil lector e identificar las percepciones, orientaciones, hitos y circunstancias que han incidido en las creencias de los docentes (Bolívar y Domingo, 2006). Esta modalidad nos permite analizar con mayor profundidad algunas de las múltiples variables que operan en las teorías implícitas de los sujetos.

La decisión de acotar el objeto de estudio a la enseñanza en segundo ciclo del nivel primario en la Ciudad de Buenos Aires ${ }^{3}$ respondió a que, en conversaciones informales, hemos observado que en ese nivel se hacen más notorias la poca presencia del género y la manifestación de dificultades para abordarlo.

Para la recolección de datos, optamos por dos tipos de instrumentos, sobre cuya utilidad hay consenso en la investigación (Bolívar y Domingo, 2006; Borg, 2003): 1) la escritura de 
relatos de vida centrados en la relación con la poesía; 2) la realización de entrevistas bajo la forma de conversaciones orientadas.

Para el estudio, convocamos como informantes a dos profesoras de nivel primario ${ }^{4}$, egresadas de institutos de formación docente de gestión pública: Antonella, graduada en 2004, y Paula, en 2014 (ambos seudónimos). Los criterios de selección considerados fueron que las docentes estuvieran ejerciendo en el segundo ciclo o lo hubieran hecho recientemente y que ambas tuvieran algún tipo de implicación personal con la lectura poética.

En un primer momento, les solicitamos la escritura de un texto en el que describieran su relación con la poesía desde la infancia hasta la actualidad. Nos interesaba que trajeran a la memoria la mayor cantidad de recuerdos e impresiones posibles, por lo que esta producción la realizarían en sus espacios y tiempos personales, para luego concretar las entrevistas. Para estas últimas, registradas en audio con consentimiento de las participantes y transcritas en su totalidad (Antonella: 37' de duración; Paula: 54'), elaboramos un guión flexible orientado a recuperar experiencias y reflexiones que las informantes consideraran significativas en relación con: 1) su perfil como lectoras de poesía; 2) la lectura de poesía en sus propias trayectorias en la educación formal, desde el nivel primario hasta la formación docente inicial; 3) sus prácticas docentes en torno al género. Estas fueron las variables tomadas en cuenta en el análisis posterior de los datos obtenidos, que se centró en el contenido narrativo, buscando relevar los temas emergentes para luego hacerlos dialogar entre sí y con conclusiones surgidas de otras investigaciones en el campo.

\section{Voces I: Antonella}

"Leía solo la poesía que me causara emoción (¿existe otra motivación?), textos que me ayudaban a sobrellevar, con más alivio, la realidad", escribe Antonella, mientras da cuenta de la construcción de una relación muy personal con la lectura poética.

$\mathrm{Su}$ acercamiento a la poesía, marcado por lo emocional, parece sostener una concepción del género: la poesía como la posibilidad de poner en palabras la experiencia ("iluminar mejor lo que me pasaba"). Juan Gelman, Ernesto Cardenal, Oliverio Girondo, César Fernández Moreno, Raúl González Tuñón y Alejandra Pizarnik eran, entre otros, los autores elegidos. Y son estos poetas los que la llevan a asociar el género "con lo inesperado" y a reivindicar para su disfrute "la 
irreverencia", los que le hablaban "de otras cosas, más zarpadas o más ocultas..." (como el desamor, la soledad, aclara en su relato).

Antonella sitúa el origen de esa relación con el género en los años posteriores a la escuela secundaria, producto de la búsqueda personal y compartida con una amiga. La exploración del discurso poético estaba orientada hacia la canción y hacia lo proveniente de "los márgenes":

Y no me acuerdo el texto, digamos el autor, pero sí que era de los márgenes, [...] era poesía que no conocíamos, que ni sabía que existía porque en la escuela no veíamos esa faceta, y que nos llamaba mucho la atención. Porque era corta, porque tenía sorpresa, era como impredecible, eso era lo que me fascinaba.

Interesa llamar la atención sobre esta configuración de los márgenes que ofrece Antonella, ya que varios de los autores que menciona están ubicados, desde hace algunas décadas, en un lugar bastante central del campo poético argentino y latinoamericano. No obstante esto, han estado ausentes en las propuestas escolares que ella recibió en su trayectoria. Poco después, Antonella definirá aquella búsqueda compartida con la expresión "traficábamos palabras", que enfatiza la distancia con lo "oficial" de la institución escolar. En el transcurso de la entrevista reaparecerán las ideas de sorpresa e impredecibilidad asociadas a esa poesía que la atrae. Y será el encuentro con esos textos y autores hasta entonces ocultos los que provocarán un punto de quiebre en su perfil como lectora del género ("construí otra mirada alrededor de la poesía").

En cuanto al acceso a los textos, los mediadores que aparecen como proveedores de información no son los convencionales: las lecturas y recomendaciones de un programa de radio, o las de un puestero de libros usados. Destaca su "afán por conocer cosas nuevas", dando cuenta de su avidez poética y de una actitud de búsqueda. Su implicación personal con la poesía sigue vigente y enfatiza el disfrute de la relectura.

Ahora bien, frente a ese contacto intenso y personal con el texto poético, el abordaje de la poesía en su trayectoria escolar se asoma desdibujado. Antonella recuerda vagamente que, en la primaria, veían "las rimas, los versos" y poemas asociados a lo romántico; además, la poesía rimada como la única existente en el horizonte escolar. Es de destacar que de esa época solo recuerda un texto, que le disgustaba ("Setenta balcones y ninguna flor", de Baldomero Fernández Moreno). Enfatiza la ausencia del "placer de la lectura" y evoca una imagen negativa del género en esa instancia de su formación: "En la escuela primaria aprendí que la poesía puede ser tediosa, aburrida o rutinaria [...]. Con el paso del tiempo, le conocí otras caras”, escribe. En cuanto al 
modo de aproximarse a la literatura en general en la escuela, lo que surge es la lectura literal y a través de cuestionarios de resolución escrita, reafirmando así las consideraciones presentadas al inicio de este trabajo.

Por otro lado, no recuerda la presencia de la poesía en la escuela secundaria, lo que nos plantea un nuevo interrogante: ¿no es recordada porque no existió o porque su presencia fue fugaz e intrascendente? Al mismo tiempo, Antonella duda en considerar poesía el acercamiento a las canciones en las clases de música, aduciendo que "no analizábamos los versos... o sea, la métrica". Evidencia aquí una concepción de la lectura de poesía en el espacio escolar centrada en los aspectos formales. Si bien antes no dudó en incluir la canción al hablar de su relación personal con el género, al momento de pensar en la escuela pone en duda su consideración como texto poético; este cuestionamiento no está dado por los textos en sí mismos sino por el abordaje que se hizo de ellos.

La pregunta por la poesía en la formación del profesorado cae en el vacío: ningún recuerdo asoma allí.

En su rol docente, Antonella nunca incluyó el género entre las lecturas con sus estudiantes de segundo ciclo: "sigue estando como separado, ¿no? La escuela de lo que fue mi trayecto...". En el transcurso de la conversación va tomando forma la idea de que ella solo concebiría como interesante abordar su lectura desde una experiencia semejante a la propia, pero considera que esto es demasiado subjetivo para el aula y desconfía de que a los chicos "les llegue"; no quiere enfrentarse al rechazo por parte de los niños pues la poesía es muy importante para ella y. Ante la fuerza del supuesto de que debe ser abordada desde lo formal, Antonella prefiere dejarla afuera (“...porque tengo incorporado lo de la métrica o lo aburrido, y no lo daría ni a palos”).

Ante la invitación a imaginar de qué modo abordaría la poesía con sus estudiantes, manifiesta tener poco conocimiento de propuestas poéticas publicadas en colecciones destinadas al público infantil. La pregunta sobre si compartiría con los chicos textos de los autores que ella disfruta y ha mencionado provoca de entrada una negación tajante. El primer argumento -espontáneo- contra la inclusión de textos de esos autores es que "hay muchas metáforas" y teme que no las interpreten. Este comentario hace emerger dos nuevos supuestos: por un lado, la idea de que los niños tendrían dificultades o imposibilidad para atribuir sentidos al discurso metafórico; por otro, pareciera que no se les debe ofrecer textos considerados complejos. 


\section{Voces II: Paula}

"Ya la palabra poesía me provoca cierta sonrisa en el rostro. [...] De un yo que viaja en el tiempo y se encuentra con una adolescente de 13-14 años que a escondidas, escribe versos en diferentes cuadernos...", escribe Paula, quien se define como lectora en un contexto familiar de no lectores. Se entusiasma al declarar una buena relación con la poesía, que en la adolescencia la ayudó a sobrellevar momentos conflictivos ("me ayudaba a poner en palabras"). El género se presenta para Paula asociado a la escritura ("a escondidas") y a la experiencia amorosa; en ese recuerdo, surgen con fuerza las canciones románticas.

Entre sus textos preferidos, menciona "Táctica y estrategia" de Mario Benedetti; también da cuenta de lecturas de Alfonsina Storni, Pablo Neruda y Jorge Luis Borges. Y, luego de aclarar que no se trata de poesía estrictamente, Paula menciona las cartas de Frida Kahlo a Diego Rivera, señalando que es el uso del lenguaje que hace Frida lo que la lleva a vincular sus escritos con el género. Este comentario cobra especial sentido cuando le preguntamos con qué asocia ella a la poesía: “...como la ola en el mar [...]. Algo en movimiento, no estático. [...] Algo que tiene un sonido propio y que no importa quién lo escuche, algo te genera. [...] para hacerte un ruido, para movilizarte". Nos interesa detenernos en esta suerte de "definición" de la poesía en la que Paula se aleja de las habituales caracterizaciones escolares del género, centradas en sus aspectos formales.

¿Quiénes mediaron para acercar a Paula a la poesía? La única referencia es una pareja que le dio a conocer textos y autores, incluidos del rock nacional. No conserva recuerdos de lectura poética en la escuela primaria. De la secundaria, solo recupera un poema de Borges, del que recuerda el tono pesimista y la conversación que hubo al respecto. Nos interesa rescatar este dato, que se asocia con el comentario que ella misma hace luego: "Las lecturas generalmente eran para discutir. No era esta cosa que se solía hacer en la primaria de responder preguntas sobre lo leído...". Además de resultar claro que Paula ya ha atravesado un proceso de reflexión sobre la lectura escolar de literatura, es de destacar que el recuerdo emerge cuando la situación de lectura le resultó significativa.

Paula reconoce en el profesorado una bisagra en su concepción de la literatura y su enseñanza, incluida la poesía. De esta etapa, valoriza con énfasis una situación de escritura de invención: la producción de un texto propio a partir de versos de poemas de autores más o menos 
consagrados, de épocas y poéticas variadas. El abordaje del género se centró en la escritura (no se promovieron situaciones de discusión en torno a los textos) y en la puesta entre signos de pregunta del modo tradicional de enseñanza de la poesía:

[el docente] nos preguntaba qué considerábamos que era una poesía, si entendíamos la poesía, si se enseña [...]. Si se enseña la literatura y cómo se enseña... No respondía al final, pero... ¿alcanza con esto de las partes, de la cantidad de versos, el tema de las estrofas, si tiene rima...?

Cabe destacar que solo dedicaron una clase a la poesía ${ }^{5}$, sin embargo, como veremos luego, esta única situación tuvo un alto impacto en la concepción de Paula sobre su didáctica.

En sus clases, Paula abordó la poesía a través de la propuesta de situaciones de escritura de invención. Cuando le planteamos la situación hipotética de diseñar una secuencia para su $7^{\circ}$ grado actual, pone el énfasis en la escritura. Surge también la intención de desarmar ideas muy instaladas en el imaginario sobre el género, como la asociación de poesía y rima. En estas preocupaciones se observa el impacto de su formación, así como en el hecho de obviar las instancias de discusión literaria.

Como en el caso de Antonella, en sus comentarios se percibe una tensión en relación con la presencia de metáforas, vistas como complejas. Por un lado, en su discurso aparece la necesidad de analizarlas y que "se entiendan", de "desglosarlas" para ver "qué pudo haber querido decir o no". Pero, al mismo tiempo, en línea con lo que sucedía en sus clases en el profesorado, Paula cuestiona la idea de dar a los chicos explicaciones completas o respuestas que clausuren, aun cuando ellos demanden certezas.

En cuanto al corpus para sus clases, no duda en incluir poemas de autores que no han escrito para niños ("el libro no te tiene que decir a vos para qué edad lo tenés que dar”). Además, enfatiza que a ella deben gustarle los textos, para poder leerlos con intensidad en la situación didáctica.

Paula siente a la poesía como un tema pendiente para ella; se considera poco preparada para su abordaje, fundamentalmente porque dice poseer un escaso conocimiento de textos y autores, que evalúa indispensable para diseñar sus clases. No obstante esto, enfatiza su voluntad de hacer un lugar a la poesía en sus clases y, como se ha expuesto, explora algunas alternativas para darle entrada.

En el cuadro 1, ofrecemos una síntesis de los resultados. 
Cuadro 1: síntesis de resultados

\begin{tabular}{|c|c|c|}
\hline & Antonella & Paula \\
\hline Perfil lector & $\begin{array}{l}\text { Implicación personal con lectura poética. } \\
\text { Poesía asociada a lo emocional y la experiencia. } \\
\text { Autores argentinos y latinoamericanos del siglo } \\
\text { XX y provenientes de la música. } \\
\text { Conocimiento y elección de autores por fuera } \\
\text { del sistema escolar. }\end{array}$ & $\begin{array}{l}\text { Implicación personal con lectura poética. } \\
\text { Poesía asociada a la escritura y la experiencia } \\
\text { amorosa. } \\
\text { Autores argentinos y latinoamericanos del siglo } \\
\text { XX y provenientes de la música. } \\
\text { Conocimiento y elección de autores por fuera } \\
\text { del sistema escolar. }\end{array}$ \\
\hline $\begin{array}{l}\text { Escolaridad } \\
\text { primaria y } \\
\text { secundaria }\end{array}$ & $\begin{array}{l}\text { Escasez de recuerdos, todos asociados con los } \\
\text { aspectos formales y el romanticismo como } \\
\text { tema. Lectura literal y a través de cuestionarios } \\
\text { de resolución escrita. } \\
\text { Evoca imagen negativa de la poesía. }\end{array}$ & $\begin{array}{l}\text { Escasez de recuerdos, excepto uno significativo: } \\
\text { lectura y discusión en torno a un poema. }\end{array}$ \\
\hline $\begin{array}{l}\text { Formación } \\
\text { docente } \\
\text { inicial }\end{array}$ & Ausencia de recuerdos de lecturas poéticas. & $\begin{array}{l}\text { Reconoce esta instancia como bisagra en su } \\
\text { concepción de la didáctica de la poesía. } \\
\text { Poesía asociada a la escritura de invención y a la } \\
\text { inclusión de textos no publicados para niños. } \\
\text { Cuestionamiento de los modos tradicionales de } \\
\text { enseñanza del género. }\end{array}$ \\
\hline $\begin{array}{l}\text { Poesía en sus } \\
\text { prácticas } \\
\text { docentes }\end{array}$ & $\begin{array}{l}\text { Negativa explícita a abordarla. } \\
\text { Rechazo de posibilidad de construir corpus con } \\
\text { textos no producidos para público infantil. }\end{array}$ & $\begin{array}{l}\text { Abordaje de la poesía a través situaciones de } \\
\text { escritura y de la pretensión de desarticular } \\
\text { estereotipos sobre el género. } \\
\text { Acepta posibilidad de construir corpus con } \\
\text { textos no producidos para público infantil. }\end{array}$ \\
\hline
\end{tabular}

\section{Discusión}

Antonella y Paula, dos maestras que se reconocen a sí mismas como lectoras y, aunque con diferente intensidad, ambas interesadas en la lectura poética. En sus relatos de vida observamos un primer punto en común: la poesía se presenta como la posibilidad de "descifrar la propia experiencia”, en palabras de Petit (1999, pp. 36-37), que agrega:

[...] es el texto el que 'lee' al lector, en cierto modo el que lo revela [...]. Los escritores nos ayudan a ponerle un nombre a los estados de ánimo por los que pasamos, a apaciguarlos, a conocerlos mejor, a compartirlos.

Mientras que el interés se tradujo en Antonella en acciones que enriquecieran su biblioteca poética, Paula reconoce la profundización en el género como una asignatura pendiente. No obstante esta diferencia en el grado de frecuentación y conocimiento del género, se observa en ambas una implicación personal con la lectura poética. En este sentido y retomando las 
conclusiones de las investigaciones sobre la incidencia del perfil lector en las actuaciones docentes (Applegate y Applegate, 2004; Granado y Puig, 2014; Munita, 2013b, entre otros), podríamos conjeturar que ambas, sobre todo Antonella, darían cuenta de la presencia del género en su propia práctica docente. En consonancia con esos estudios, entre las hipótesis que manejábamos al inicio de este trabajo atribuíamos la escasa o nula presencia del género en las aulas a una supuesta inexistencia de lectura poética por parte de los docentes. Creíamos, con Boland (2011), que "un mediador formado en poesía y lector sabrá recrear un espacio íntimo y a la vez compartido donde los chicos se acerquen a la lectura de poesía" (p. 49).

Sin embargo, el relato de Antonella pone en tela de juicio esa hipótesis, nos hace suponer que el perfil lector es condición necesaria pero no suficiente, y nos devuelve a las investigaciones sobre las creencias, en particular al impacto de las trayectorias escolares. ¿Qué ha sucedido en su formación para obturar que una experiencia personal tan intensa tenga impacto en su práctica docente? ¿Por qué cobra tanta fuerza la percepción de la escuela como un espacio donde la experiencia poética no está habilitada?

A la escasa presencia que la poesía tuvo en la educación literaria de Antonella se suma una aproximación al texto poético que "empobrece la experiencia de lectura limitándola a responder un cuestionario por escrito y a clasificar el tipo de rima" (Cañón y Hermida, 2012, p. 58) y que confirma las perspectivas empobrecedoras y sesgadas a las que aludían Mathieu (2012) y Bombini y Lomas (2016). Esta situación la lleva a afirmar de manera tajante que "no lo daría ni a palos" y a excluir la poesía de sus clases, evidenciando el peso que tiene en sus creencias la concepción de que el abordaje formal (configurado como mero reconocimiento de recursos, sin vincularlos con la producción de sentidos en el poema) es el único posible en el aula. En correlato con esto, Antonella no concibe la posibilidad de proponer a sus estudiantes una aproximación al texto poético como el que ella privilegia en su lectura personal, es decir, desde la experiencia vital; se aleja así de la conclusión de Granado y Puig (2014) acerca del traslado al aula de las propias prácticas lectoras. Habría, entonces, en relación con la poesía en el espacio escolar, ciertos modos de leer legítimos (Bombini, 1989) que excluirían el modo de leer personal de Antonella.

Otro de los contenidos que pesan en las creencias de esta docente se refiere al corpus. Como hemos visto, en su relato contrapone lo aburrido y rutinario de sus lecturas escolares con la impredecibilidad, la sorpresa y la transgresión que le aportan los textos hallados -y privilegiados 
por ella- en circuitos alternativos de circulación. Sin embargo, no se plantea la posibilidad de incluir estos últimos en el diseño de sus clases debido a que la marcada presencia de metáforas la lleva a atribuirles una complejidad que excedería las posibilidades de los niños. En esta preocupación parece asomarse "el miedo a la aparente dificultad que implica una zona del arte más inasible y salvaje que otras" del que habla Bajour (2013). La complejidad sería, entonces, un criterio de peso en las creencias de Antonella sobre la conformación del corpus escolar. Por otro lado, ante la pregunta de cómo abordaría la poesía con los niños, su primera respuesta fue que desconocía la oferta del mercado destinada a ellos, lo que podría esconder el supuesto de que el corpus debería estar conformado únicamente por esos textos.

El caso de Paula se presenta diferente en algunos aspectos. Si bien carece de recuerdos sobre la poesía en la escuela primaria, señala que en el secundario las lecturas eran "para discutir", en una práctica que parecería acercarse a las propuestas de conversación literaria como dispositivo didáctico (Chambers, 2007). Por otro lado, en su relato no da cuenta del abordaje formal que tanto impactó en Antonella.

Aunque Paula no revela mucho más acerca de cómo fue leída la poesía en su trayectoria escolar, hemos visto que ella reconoce en su formación docente inicial un quiebre en sus creencias sobre la didáctica de la literatura y de la poesía en particular, ya que habilitó el cuestionamiento de los modos tradicionales de su enseñanza y de la construcción del corpus. Con respecto a este último, la propuesta vivenciada por esta docente en su formación está alineada con la apertura del canon poético que promueve Bajour (2004) y, como hemos visto, se tradujo en que ella no duda en seleccionar para sus clases textos no escritos para niños.

Creemos que la puesta en cuestión de la enseñanza tradicional del género no se dio solo a través de las intervenciones orales del docente referidas por Paula, sino también a través del modo de leer que propuso para la poesía, que podríamos enunciar como leer para escribir, para producir un texto propio, otorgándoles sentidos personales a los versos en su nueva configuración. Esta práctica remite a muchas consignas de producción de los talleres de escritura impulsados por el grupo Grafein, sostenidas en la idea de que "leer y escribir son prácticas que se reenvían una a la otra", pues "escribo a partir de otros textos y mi lectura es en sí misma una actividad que se asimila a la escritura" (Frugoni, 2006, p. 22). Es decir, un modo de leer bien diferenciado de las perspectivas exclusivamente formales que antes mencionamos. 
La vivencia propiciada por este dispositivo didáctico en torno a la literatura impactó de tal modo en Paula que busca replicarlo en sus clases, sumado a su preocupación por desarticular los estereotipos en torno al género. En el imaginario de Paula, la didáctica de la poesía está fuertemente asociada a la producción por parte de los estudiantes $\mathrm{y}$, al mismo tiempo, no logra imaginar aún situaciones de discusión literaria sobre los textos.

\section{Algunas conclusiones}

Los casos de Antonella y Paula confirman la complejidad de la situación de la poesía en la escuela con la que iniciamos este artículo.

En cuanto a la incidencia del perfil lector del docente en sus prácticas, el estudio realizado nos lleva a concluir que, si bien necesario, no constituye una condición suficiente para asegurar la presencia del género en las aulas ni un abordaje interesante. Los datos obtenidos reafirman el fuerte impacto de las trayectorias escolares en esas prácticas, superador incluso del impacto del perfil lector.

Decíamos más arriba que la investigación educativa asume diferentes posiciones acerca de la incidencia de la formación docente en las creencias. Los casos presentados parecen inclinarse a favor de reconocer esa incidencia. Para Antonella, la formación de grado ni siquiera creó una ocasión que le permitiera revertir sus creencias sobre la didáctica de la poesía consolidadas en sus trayectorias escolares previas. En cambio, para Paula supuso una experiencia fundante de un nuevo modo de pensarla:

[...] la experiencia es lo que me pasa y lo que, al pasarme, me forma o me transforma, me constituye [...]. Por eso el sujeto de la formación no es el sujeto de la educación o del aprendizaje sino el sujeto de la experiencia: es la experiencia la que forma (Larrosa, 2003, p. 3).

Atravesar la experiencia de un modo de leer diferente en el aula habilitó a Paula para pensar sus prácticas desde una perspectiva superadora de los modos históricamente dominantes en la enseñanza de la poesía. No atravesarla pudo suponer para Antonella -conjeturamossuspender la potencia de su relación con la poesía a la hora de entrar al aula. Si bien la experiencia "no puede ser causada, no puede ser anticipada como un efecto a partir de sus causas", como nos recuerda Larrosa, sí es posible "cuidar que se den determinadas condiciones 
de posibilidad" (2013, p. 40). Es esta idea la que nos interesa recuperar en el deseo de que nos ayude a pensar y mejorar la formación docente inicial.

En función de este objetivo, los resultados obtenidos nos permiten esbozar algunas líneas de actuación que podrían explorarse o fortalecerse (en muchos casos ya tienen lugar, como hemos visto en Paula y como refiere Bajour [2003, 2016]): ofrecer un corpus amplio y lo más variado posible en cuanto a las líneas estéticas, que dé a conocer las nuevas propuestas poéticas que hoy vemos en colecciones de literatura para niños pero que incluya también textos no producidos especialmente para un público infantil; diversificar los modos de leer poesía en el aula, recuperando las prácticas de lectura privada de quienes tienen una implicación personal con el género, e incluyendo, entre otras, situaciones de discusión literaria que favorezcan la construcción personal y compartida de sentido de los textos; revisar el modo de incluir la perspectiva formal, de modo tal que resulte significativa y pueda reflexionarse sobre su impacto en la producción de sentidos de los poemas; diseñar situaciones de escritura poética a partir de consignas de producción que permitan acercarse (y apropiarse) al género desde perspectivas lúdicas y reflexivas. En todos estos casos (y en otros que podrían diseñarse), se trata de explorar líneas de acción orientadas a proveer a los docentes en formación de experiencias que enriquezcan su relación con la poesía y su forma de concebir la educación poética.

\section{Agradecimientos}

La versión original de este artículo fue presentada como trabajo final en el Máster en Libros y Literatura Infantil y Juvenil organizado por la Universidad Autónoma de Barcelona y el Banco del Libro de Venezuela (2016). Un agradecimiento especial al Dr. Felipe Munita por el diálogo generoso al tutorizar este trabajo.

\section{Referencias}

Andricaín, S. y Rodríguez, A.O. (2003). Escuela y poesía. Buenos Aires: Lugar.

Applegate, A. y Applegate, M. (2004). The Peter effect: Reading habits and attitudes of preservice teachers. The Reading Teacher, 57(6), 554-563. 
Bajour, C. (2004). La mirada poética en la biblioteca: una experiencia de Ateneo para bibliotecarios. Imaginaria: Revista Quincenal sobre Literatura Infantil y Juvenil, 138. Recuperado de http://www.imaginaria.com.ar/13/8/mirada-poetica.htm

Bajour, C. (2013). Nadar en aguas inquietas: una aproximación a la poesía infantil de hoy. Imaginaria: Revista Quincenal sobre Literatura Infantil y Juvenil, 332. Recuperado de http://www.imaginaria.com.ar/2013/09/nadar-en-aguas-inquietas-una-aproximacion-a-lapoesia-infantil-de-hoy/

Bajour, C. (2016). Poesía, voz y cuerpo. Una experiencia de poesía "infantil" contemporánea con profesorado de primaria. Textos de Didáctica de la lengua y la literatura, 72, 24-29.

Birello, M. (2012). Teacher cognition and language teacher education: Beliefs and practice. A conversation with Simon Borg. Bellaterra Journal of Teaching \& Learning Language \& Literature, 5(2), 88-94. DOI: http://dx.doi.org/10.5565/rev/jt13.464

Boland, E. (2011). Poesía para chicos. Rosario: Homo Sapiens.

Bolívar, A. y Domingo, J. (2006). La investigación biográfica y narrativa en Iberoamérica: campos de desarrollo y estado actual. Forum Qualitative Social Research, 7(4), art. 12. Recuperado de http://www.qualitative-research.net/index.php/fqs/article/view/161/357

Bombini, G. (1989). La trama de los textos. Buenos Aires: Libros del Quirquincho.

Bombini, G. y Lomas, C. (2016). La educación poética. Textos de Didáctica de la Lengua y la Literatura, 72, 4-7.

Borg, S. (2003). Teacher cognition in language teaching: A review of research on what language teachers think, know, believe, and do. Language Teaching, 36, 81-109. DOI: https://doi.org/10.1017/S0261444803001903

Cambra, M. (2000). Introducció. El pensament del professor: formació per a la pràctica reflexiva. En A. Camps, I. Ríos, M. Cambra (Coords.). Recerca i formació en didàctica de la llengua (pp. 161-171). Barcelona: Graó.

Cañón, M. y Hermida, C. (2012). Literatura en la escuela primaria. Buenos Aires: Novedades Educativas.

Chambers, A. (2007). Dime. México: FCE.

Colomer, T. (2005). Andar entre libros. La lectura literaria en la escuela. México: FCE.

Dubois, M.E. (1990). El factor olvidado en la formación de los maestros. Lectura y Vida, 11(4), 32- 35 . 
Dueñas, J. D., Tabernero, R., Calvo V. y Consejo, E. (2014). La lectura literaria ante nuevos retos: canon y mediación en la trayectoria lectora de futuros profesores. Ocnos, 11, 21-43. DOI: http://dx.doi.org/10.18239/ocnos_2014.11.02

Frugoni, S. (2006). Imaginación y escritura. Buenos Aires: Libros del Zorzal.

Granado, C. y Puig, M. (2014). ¿Qué leen los futuros maestros y maestras? Un estudio del docente como sujeto lector a través de los títulos de libros que evocan. Ocnos, 11, 93-112. DOI: http://dx.doi.org/10.18239/ocnos_2014.11.05

Larrosa, J. (2003, noviembre). Algunas notas sobre la experiencia y sus lenguajes. Conferencia en Seminario Internacional "La Formación Docente entre el siglo XIX y el siglo $X X I^{\prime \prime}$. Buenos Aires, Ministerio de Educación, Ciencia y Tecnología de la Nación. Recuperado de http://www.me.gov.ar/curriform/publica/oei_20031128/ponencia_larrosa.pdf

Larrosa, J. (2013). La experiencia de la lectura. México: FCE.

Mathieu, C. (2012, septiembre). Educación estético-literaria: la poesía en la formación de lectores. Comunicación en IV Jornadas de Poéticas de la Literatura Argentina para Niños. $\quad$ La $\quad$ Plata. Recuperado de http://www.memoria.fahce.unlp.edu.ar/trab_eventos/ev.1606/ev.1606.pdf

Munita, F. (2013a). El niño dibujado en verso: aproximaciones a la nueva poesía infantil en la lengua española. Anuario de Investigación en Literatura Infantil y Juvenil, 11, 105-117.

Munita, F. (2013b). Creencias y saberes de futuros maestros (lectores y no lectores) en torno a la $\begin{array}{lllll}\text { educación } & \text { literaria. } & \text { Ocnos, } & \text { 9, } & \text { 69-87. }\end{array}$ http://dx.doi.org/10.18239/ocnos 2016.15.2.1140

Munita, F. (2014). El mediador escolar de lectura literaria. Un estudio del espacio de encuentro entre prácticas didácticas, sistemas de creencias y trayectorias personales de lectura (Tesis doctoral). Recuperado de: http://www.tdx.cat/bitstream/handle/10803/313451/fm1de1.pdf;jsessionid=B24D4ACCB 66CDEDD6BAAB994C6D02A77.tdx1?sequence $=1$

Negri, M. y Correa, A. (2014). Poesía en la escuela. Buenos Aires: Poesía en la Escuela Ediciones.

Petit, M. (1999). Nuevos acercamientos a los jóvenes y a la lectura. México: FCE. 
Ramos, M. C. (2012). Lectura de poesía en la escuela: el pez que no se ve. Cuatrogatos. Recuperado de http://prensa.uncoma.edu.ar/index.php/es/especiales/24-especiales/1019lectura-de-poesia-en-la-escuela-el-pez-que-no-se-ve-por-maria-cristina-ramos

\section{Información sobre la autora:}

Florencia Lamas es Licenciada y Profesora en Letras por la Universidad de Buenos Aires, Especialista en Literatura Infantil y Juvenil (CEPA) y Magíster en Libros y Literatura Infantil y Juvenil por la Universidad Autónoma de Barcelona. Ha coordinado talleres de literatura en el nivel primario y en programas de actualización docente. Actualmente se desempeña como docente en profesorados de educación primaria y en secundario de adultos, y como editora.

Email: lamas florencia@yahoo.com.ar

Para citar este artículo:

Lamas, F. (2017). Poesía en la escuela: los maestros, sus lecturas y sus creencias. Bellaterra Journal of Teaching \& Learning Language \& Literature, 10(4), 32-48. DOI: https://doi.org/10.5565/rev/jt13.699

Notas

1 Ver, entre otros: Bajour, 2013; Cañón y Hermida, 2012; Mathieu, 2012; Negri y Correa, 2014. Muchos especialistas destacan otros indicadores sobre esta marginalidad: la escasez de producción teórica y de ediciones de poesía destinadas al público infantil, aunque actualmente se observa un crecimiento (Bajour, 2013; Boland, 2011; Munita, 2013a).

${ }^{2}$ Referencias similares pueden verse en Andricaín y Rodríguez, 2003; Bajour, 2004; Cañón y Hermida, 2012.

${ }^{3}$ En el actual sistema educativo de la Ciudad de Buenos Aires, la Educación Primaria consta de siete niveles agrupados en dos ciclos: primer ciclo va de $1^{\circ}$ a $3^{\circ}$ grado, y segundo ciclo, de $4^{\circ}$ a $7^{\circ}$.

${ }^{4}$ En la Ciudad de Buenos Aires, el Profesorado de Educación Primaria prepara para la enseñanza en primero y segundo ciclo. En su formación Antonella y Paula se formaron con planes de estudio diferentes, en ambos casos cursaron materias que incluían entre sus contenidos la literatura y didáctica.

${ }^{5}$ Esto responde a la escasa carga horaria del Seminario de Literatura en la Educación Primaria; los cursos se desarrollan en aproximadamente 13 clases de 3 hs cátedra cada una. 